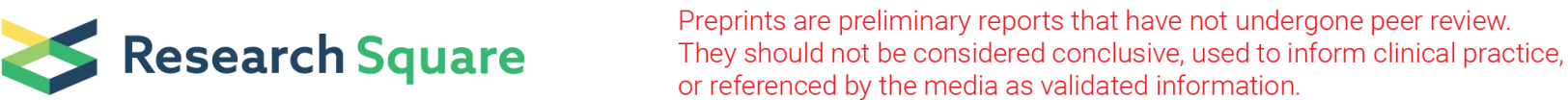

\section{Prevalence and factors associated with suicidal behavior among adolescents with epilepsy at Mulago and Butabika national referral hospitals in Uganda.}

Hillary Kuteesa ( $\square$ larrycutesir@gmail.com )

Makerere University College of Health Sciences https://orcid.org/0000-0001-6305-6691

Catherine Abbo

Makerere University College of Health Sciences

Winstons W Muhwezi

Makerere University College of Health Sciences

Research article

Keywords: suicidal behavior, adolescents, epilepsy, psychiatric comorbidity, coping, social support

Posted Date: February 6th, 2020

DOl: https://doi.org/10.21203/rs.2.22768/v1

License: (c) (1) This work is licensed under a Creative Commons Attribution 4.0 International License.

Read Full License 


\section{Abstract}

\section{Background}

Suicide is the $3 \mathrm{rd}$ leading cause of death among young people. Patients with epilepsy are 2 times more likely to have suicidal ideation and 3 times more likely to plan suicide attempt. In addition to seizures, these young people experience a variety of psychiatric illnesses like depression and anxiety. Social support and coping are known to have an effect on suicidal behavior in adolescents with epilepsy. There's scanty data on this subject in Uganda. The purpose of this study was to determine the prevalence of suicidal behavior among adolescents with epilepsy at Butabika and Mulago National Referral Hospitals and associated factors.

Methods

Between 1 st August 2017 and 1 st February 2018, we sampled 223 adolescents from Butabika and Mulago National Referral Hospitals using a cross sectional study design. We used a Demographics Questionnaire, Mini International Neuropsychiatric Interview for Children and Adolescents-DSM-IV-TR version (MINI-KID), Brief COPE, and Multidimensional Scale of Perceived Social Support (MSPSS) to collect data. Data Entry was done using Epi Data and analyzed with Stata version 14. The dependent variable was suicidal behavior and independent variables were socio-demographic characteristics of adolescents and caregivers, epilepsy related factors, psychiatric co morbidity, coping strategies and perceived social support. Bi-variate and Multi-variate analyses were done to describe the associations between the dependent and independent variables.

Results

Of the 223 adolescents we recruited, (123)55.2\% were male, $52.9 \%$ were aged $14-17$ years. The prevalence of suicidal behavior was $30.5 \%$. Major depression was most strongly associated with suicidal behavior ( $\mathrm{aOR}=9.3, \mathrm{Cl}=4.3-20.1, \mathrm{p}<0.001)$. Adolescents having post primary education were more likely to have suicidal behavior $(\mathrm{aOR}=2.2, \mathrm{Cl}=1.0-4.9, \mathrm{p}=0.046)$. Venting as a coping strategy was found to increase the likelihood of having suicidal behavior $(\mathrm{aOR}=2.7, \mathrm{Cl}=1.2-6.2, \mathrm{p}=0.017)$ whereas perceived family social support $(\mathrm{aOR}=0.4, \mathrm{Cl}=0.2-0.8, \mathrm{p}=0.017)$ and the use of the active coping strategy $(\mathrm{aOR}=0.4$, $\mathrm{Cl}=0.2-0.9, \mathrm{p}=0.033$ ) were protective against suicidal behavior.

Conclusions

Prevalence of suicidal behavior in adolescents with epilepsy is high. Major depression is associated with suicidal behavior while perceived family social support is protective against suicidal behavior.

\section{Background}

Epilepsy is one of the few medical disorders associated with an increased risk of suicide in adults as well children and adolescents [1]. The risk of suicide in adolescents with a history of psychiatric disturbances 
is greatest at the onset of epilepsy [2]. Adolescence is a unique time of life when there are many dynamic changes in the physical body, sexual development, socialization, and cognition [3]. Normal physiologic and psychological alterations can affect the course of the epilepsy and the considerations for medication selection [4]. Having a chronic condition like epilepsy for adolescents makes the situation dire and is a fertile ground for suicidal behavior [5].As of 2013, suicide was the second leading cause of death among 15-24 year old people worldwide [6]. It is also known that suicide risk is higher in people living with epilepsy than in the general population $[7,8]$ and in a review of 21 studies, the average prevalence of suicide in epilepsy was $11.5 \%$ compared to $1.2 \%$ in general population with $46 \%$ having attempted suicide [9].

A few studies have examined suicidality in children and adolescents with epilepsy. In a case control study, suicidal ideation was found in $17 \%$ of 48 children with complex partial seizures (CPS) and $18 \%$ of 39 with childhood absence epilepsy (CAE) and suicidal intent in $8 \%$ and $11 \%$ of the CPS and CAE groups respectively [10]. In another case control study of 171 children and adolescents aged 5 to 16 years in USA, suicidal ideation was found to be $20 \%$ higher in those with epilepsy than in the normal group [11]. Children and adolescents with epilepsy aged 7 to 18 years old had suicidal ideation with intent in $4.3 \%$ and without intent in $11 \%$ [12].

Epilepsy is a chronic neurological condition that causes a range of challenges for the sufferers[13] including; unpredictable seizures, injury from the seizures, stigma, psychiatric disorders, restrictions from activities like driving, swimming, cooking, among others [5]. Multiple factors are reported to be associated with suicidal behavior among adolescents with epilepsy including socio-demographic factors, psychiatric comorbidity [14], seizure related factors [15], coping strategies [16], and perceived social support [17]. Other factors that might be specific to Africa include; mythical beliefs and demonization of epilepsy[18], scarce medical care, large treatment gap $[19,20]$, and crippled health care systems; all of which make the quality of life of these adolescents with epilepsy poor [21, 22].

Criminalization and stigmatization of suicidal behavior worsens the situation in the Ugandan setting. People still hold negative attitudes towards suicidal behavior and suicide is still a taboo [23]. According to Ugandan laws, attempting suicide is a criminal offence punishable by imprisonment as is the case in many commonwealth countries [24]. There is paucity of research on suicidal behavior among adolescents with epilepsy in Africa and specifically in Uganda. In this paper, we report the prevalence and factors associated with suicidal behavior among adolescents with epilepsy at Butabika and Mulago National Referral Hospitals.

\section{Methods}

\section{Aims}

To determine the prevalence of suicidal behavior among adolescents with epilepsy at Butabika and Mulago National Referral Hospitals and associated factors. 


\section{Study Setting}

The study which informs this paper was conducted at the Child and Adolescent Mental Health Clinic of Butabika National Mental Referral Hospital and the Pediatric Neurology Clinic and Mental Health Clinic of Mulago National Referral Hospital for a period of 6 months, between August 2017 and February 2018. Butabika National Mental Referral Hospital is located $12 \mathrm{Kms}$ east of Kampala City. It is the only national referral mental health institution providing specialized care to people with mental illnesses as well as teaching for all cadres specializing in mental health ranging from nursing cadres to postgraduate students. In addition, it provides out-patient services to the people from surrounding areas. It is the second biggest hospital in Uganda with a bed capacity of 550. However, patient numbers often range between 720-780. On average, the hospital attends to approximately 25,000 patients annually. The Child and Adolescent Mental Health clinic in the hospital offers general child and adolescent psychiatry services, inpatient services, psychological therapies, occupational therapies, social services, dispensary and referral to other specialized services. The bed capacity is 40 . The admission age limit for the clinic is 17 years. Once the adolescent turns 18 years, they are transferred to the adult mental health clinic. The clinic runs from Monday to Friday excluding public holidays. A typical clinic day involves first getting a number in the queue (first come first serve basis) and submitting medical forms (which include patient's outpatient number) to the records office to access patient's file, which is then forwarded to the clinician on duty. The client then waits in the queue till called and seen by the clinician. Emergencies are attended to as soon as they arrive. Psychiatric Nurses, Clinical officers, Medical officers, Senior House Officers and Psychiatrists attend to the patients. The Child and Adolescent Mental Health clinic attends to 250-300 children and adolescents every week. Between $50-62 \%$ of those attending have epilepsy and approximately $25 \%$ of these are newly diagnosed with epilepsy every month [25].

Mulago hospital is the largest in Uganda and is located $3 \mathrm{Kms}$ from the city center. It is the National Referral for the entire country. It is also the general hospital for metropolitan Kampala. It has an official bed capacity of 1,790. It is a teaching hospital for Makerere University College of Health Sciences, Mulago School of Nursing and Midwifery and Mulago Paramedical Schools. The Pediatric Neurology Clinic is under the Department of Pediatrics and Child Health and is run as an outpatient specialized clinic catering for children with neurological disorders once a week every. It serves as a referral outpatient clinic for the neurological cases from all over the country. Annually, the clinic sees about 300 new patients. On each clinic day, 40-70 children aged 2 months to 17 years are attended to. The clinic accepts an upper age limit of 17 years. Epilepsy contributes to $60 \%$ of the attendance. On the other hand, the Mental Health Clinic is the Psychiatric out patient's clinic at Mulago Hospital which runs between 8:00am - 3:00 pm from Monday to Friday. The clinic offers psychiatric, psychological and occupational therapies for general adult psychiatric disorders, child and adolescent psychiatric disorders and epilepsy. The clinic attends to between $20-40$ patients daily. Between $40-60 \%$ of the clinic attendance is due to epilepsy.

\section{Study design}


We used a descriptive cross sectional study design.

\section{Study Participants}

These were adolescent patients with epilepsy aged 10-17 years. They were required to have been accompanied by a caregiver who would consent on their behalf. The study inclusion criteria were; (i) having a diagnosis of epilepsy as per medical records in patient files and clinical interview, (ii) falling in the age range of 10-17 years, and (iii) providing assent and informed consent by caregivers. Those excluded were those that did not understand the questions or who were unable to go through with the interview.

\section{Sample Size Estimation}

A total sample size of 223 participants was estimated using the formula for finite populations [26]. A prevalence ( $p$ ) of $50 \%$ was used because no study of prevalence and of suicidal behavior in adolescents had been done in our setting. Combined, the study sites received about 88 adolescents per month and for the study period of 6 months which totaled to approximately 528 adolescents. Using the finite population correction factor calculation of sample size, the sample was adjusted for available population as shown $\mathrm{n}=\mathrm{n}_{\mathrm{o}} \mathrm{N} /\left(\mathrm{n}_{\mathrm{o}}+(\mathrm{N}-1)\right)$ where $\mathrm{n}_{0}=385$ and $\mathrm{N}=528$.

\section{Sampling Procedure}

A consecutive sampling method with a random start was used due to time constraints. We recruited all available adolescents who met the inclusion criteria during the study period until the desired sample size was achieved. The study participants were recruited every Monday - Friday at Butabika Hospital Child and Adolescent Mental Health Clinic and Mulago Mental Health Clinic. At the Pediatric Neurology Clinic in Mulago Hospital, participants were recruited on the clinic day (Thursday). Approximately 2-5 patients were recruited per day from Monday to Friday over a period of 28 weeks.

\section{Study procedure}

Four research assistants (RA), who were psychiatric nurses were trained on how to administer the study tools and ethical conduct. Two were deployed at each hospital and worked hand in hand with the staff on given clinic days. The staff of all the clinics had been oriented about the study aim and target population. Upon arrival to the clinic, anyone of the available nursing staff received patient's medical forms and forwarded them to the records department which then traced the patient files and gave them to the nurse who would then queue them up for the clinicians on duty. The clinicians on duty then forwarded the adolescents with epilepsy to the research team. A brief clinical interview and review of the patient's file was done to verify the diagnosis of epilepsy according the operational definition of this study. The 
research team then explained the purpose of the study and obtained informed consent from the primary caregiver and assent from the adolescents, signified by affixing of a thumbprint or a signature. Those who met the inclusion criteria were then enrolled in the study. They were led to a consultation room and the data was collected using interviewer administered pretested questionnaires. The questions were mainly addressed to the adolescent and where clarification was needed, the care giver was asked. Each interview lasted approximately 20 minutes. Upon completion, the participant was helped to get their medication. The filled in questionnaires and patients file were labeled with a study number and then locked away for safe custody pending data entry. Adolescents who were found to be suicidal or having any other psychiatric disorders were forwarded to the clinician/ psychiatrist/ psychologist on duty for further management.

\section{Study Measures}

The dependent variable was suicidal behavior. Independent variables were; adolescent sociodemographic characteristics, primary caregiver socio-demographic characteristics, seizure related characteristics, psychiatric comorbidity, coping and perceived social support.

\section{Study Instruments}

All instruments were interviewer administered to all the adolescents to reduce variability in understanding of questions due to differences in literacy levels.

\section{Diagnosis Of Epilepsy}

A brief clinical interview was done. The adolescents and or their caregivers were asked if the adolescent had ever experienced unprovoked seizures more than 24 hours apart. A review of the patient's file was done to find evidence of epilepsy in the notes of the previous visits. These two sources of information were compared and used to verify the diagnosis of epilepsy as operationally defined. Those whose clinical description matched that of the operational definition and those who had their medical records supportive of epilepsy were considered to have epilepsy.

A demographics questionnaire was used to collect socio-demographic data about adolescents and their caregivers. Variables in the tool included the patient's age, sex, tribe, address, religion, level of education, address, socio-economic status and caregiver socio-demographics relating to relationship with the adolescent, marital status, house ownership, occupation, level of education and level of family income.

Mini International Neuropsychiatric Interview For Children And Adolescents (MINI-KID) was used to assess suicidal behavior and psychiatric comorbidity. It is a short structured diagnostic interview for DSM-IV and ICD-10 psychiatric disorders. Although the MINI-KID has not been validated in Uganda, it has been internationally validated in various studies in various African cultures and it has been used in many 
previous studies in Uganda [28-30]. Substantial to excellent MINI-KID to K-SADS-PL (Kiddie - Schedule for Affective Disorders and Schizophrenia- Present and Life-time) concordance was found for syndromic diagnoses of any mood disorder, any anxiety disorder, any substance use disorder, and behavioral disorder.

Suicidal behavior was assessed with the suicidality module of the MINI-KID. This module includes questions on hopelessness, deliberate self-harm, death wishes, suicidal ideas, plans and attempts. Responses are either YES or NO with each having a pre-assigned score. Any score $\geq 1$ was translated to meeting the criteria for suicidal behavior. Suicide risk scores were low, moderate and high when the scores were $1-8,9-16$, and $\geq 17$ respectively [27]. The categories of suicidal behavior were as operationally defined, that is; passive suicidal ideation, active suicidal ideation and suicidal attempts. Passive suicidal ideation was made up of two questions, one on death wishes in the past month and another on death wishes in one's lifetime. Active suicidal ideation included two questions, one on having suicide plans and another on having taken active steps to prepare for suicide. Suicide attempts was made up of two questions, one on suicide attempts in the past month and another on suicide attempts in the lifetime. Frequencies and percentages were used to describe these categories.

Psychiatric Comorbidity was measured with the major depressive episode module, generalized anxiety disorder module, alcohol dependence/abuse module, substance dependence/abuse(non-alcohol) module, and psychotic disorders and mood disorders with psychotic features modules.

The Brief Coping Orientation to Problems Experienced (Brief COPE) was used to assess coping strategies [31]. A previous report to establish the reliability and validity of the scale indicated a high Cronbach's alpha values for some domains such as Religion $(a=0.82)$ and Substance use $(a=0.90)$. Other domains indicated acceptable Cronbach's alpha values of between 0.73 for humor and 0.50 for venting. The tool has 28 four-point Likert scale questions, with responses coded as; $1=1$ haven't been doing this at all, $2=1$ have been doing this a little bit, $3=\mathrm{I}$ have been doing this a medium amount, and $4=\mathrm{I}$ have been doing this a lot. The tool has 14 domains with two questions contributing to each domain. In this study, YES was taken to be any responses 3 and 4 on the scale. And for each domain, YES was taken to be anyone who had 2 YES responses on each question. The tool has been used in some studies in Uganda however has not been validated[32].

Multidimensional Scale of Perceived Social Support - (MSPSS) was used to assess perceived social support [33]. The tool was validated and adapted for use in the Ugandan setting and was found to have good psychometric properties with Cronbach alpha values $0.79,0.80$, and 0.82 on all 3 sub-scales (Family, Friends and Significant other respectively) and internal consistency of 0.83 [34]. The MSPSS is a brief self-report questionnaire with 12 items that subjectively measure perceived social support. Each of the three subscales has four items with 5-point Likert scale with response codes as $1=$ Strongly Disagree, $2=$ Mildly Disagree, $3=$ Neutral, $4=$ Mildly Agree and $5=$ Strongly Agree. In this study all who circled option 4 or 5 were taken as YES responses and the rest as NO. For each domain containing 4 questions, all who had 3 or 4 YES responses for the four questions were taken as YES. 


\section{Seizure Related Characteristics}

The following questions assessed seizure characteristics and were answered by the patient and or parent/guardian. The questions were asked irrespective of epilepsy treatment status and included;

how many seizures have you had in the last 1 year?, have you sustained any physical injuries from seizures?, how old were you when the epilepsy started?, how long have you had epilepsy?, how long have you been taking anti epilepsy drugs?, how many anti-epilepsy drugs are you currently taking?, how often do you miss taking your anti epilepsy drugs?, and is there family history of epilepsy?.

All study tools were translated from English to Luganda and back translated by two independent linguists. We pre-tested the tools on the first 20 adolescents with epilepsy at Butabika Hospital to assess understanding of questions and responding appropriately. The outcome helped in modification of the tools prior to data collection. Some minor modifications to the tools included, study site inclusion, and rearranging the MSPSS Likert scale correctly in the translated tools.

\section{Statistical analysis}

Data was entered using EPI DATA version 3.1 and exported into STATA version 14 for analysis. Frequencies were used to describe the sample demographic characteristics. The prevalence of suicidal behavior was calculated as the total number of adolescents who met the criteria on the Suicidality Module of the MINI-KID as the numerator and the total number of respondents as the denominator. Simple logistic regression was done to determine bivariate associations between independent variables and outcome (suicidal behavior). Odds ratio was used as a measure of association and a statistical significance was determined using a p-value of 0.05 and a $95 \%$ confidence interval. At multivariate analysis, all variables with significant association at bivariate analysis were included in the multivariable logistic regression model. We used the backward elimination regression model method to drop variables with high and or insignificant p-values. Adjusted odds ratio was used as the measure of association and statistical significance was determined using a $p \leq 0.05$.

\section{Results}

We attained a sample size of 223. There were 104 adolescents interviewed from Butabika hospital and 119 adolescents from Mulago national referral hospital. At Mulago National referral hospital, 71 adolescents were interviewed at the Mental Health Clinic while 48 were interviewed at the Pediatric Neurology Clinic.

The prevalence of suicidal behavior among adolescents with epilepsy was $30.5 \%$. Most of those who had suicidal behavior had low suicide risk $42(62 \%)$ followed by those with High suicide risk $14(20 \%)$ and finally those with moderate suicide risk were the least $12(18 \%)$. Table 1 shows the different categories of suicidal behavior. 
Table 1: Categories of Suicidal Behavior among the adolescents with epilepsy at Butabika and Mulago Hospitals

\begin{tabular}{|c|c|c|c|}
\hline Suicidal Behavior & Characteristic & $\begin{array}{l}\text { Frequency }(n= \\
68)\end{array}$ & Percentage (\%) \\
\hline \multirow{2}{*}{$\begin{array}{l}\text { Passive suicidal } \\
\text { ideation }\end{array}$} & Death wishes in past month & 41 & 60.3 \\
\hline & Death wishes -Lifetime & 44 & 64.7 \\
\hline \multirow[t]{2}{*}{ Active suicidal ideation } & Suicide Plans & 7 & 10.3 \\
\hline & $\begin{array}{l}\text { Active steps to prepare for } \\
\text { Suicide }\end{array}$ & 5 & 7.4 \\
\hline \multirow[t]{2}{*}{ Suicide attempts } & Suicide Attempt in past month & 6 & 8.8 \\
\hline & Suicide attempt-Lifetime & 8 & 11.8 \\
\hline \multicolumn{4}{|c|}{$\begin{array}{l}\text { The sociodemographic characteristics of the adolescents are detailed below; majority of the } \\
\text { participants were male } 55.2 \%(123) \text {; aged } 14-17 \text { years } 52.9 \% \text { (118); belonged to the Ganda tribe } \\
60.1 \%(134) ; \text { lived in urban areas } 59.6 \%(133) ; \text {; belonged to the Catholic faith } 30 \%(67) \text {, Anglican faith } \\
27.4(61) \text { and born-again faith } 20.2 \% \text { (45); had attained at least primary education } 70.0 \%(156) \text { and } \\
\text { secondary education } 27.8 \%(62) \text {; had primary caregiver as both parents } 48.4 \%(108) \text {, mother } 27.8 \% \\
\text { (62) and grandparents } 10.3 \%(23) \text {. }\end{array}$} \\
\hline
\end{tabular}

Caregiver sociodemographic characteristics are detailed below; $59.3 \%$ (131) of caregivers were married/cohabiting, Widowed for $15.8 \%$ (35), Separated/divorced for $14.9 \%$ (33) and $10 \%$ (22) single. Majority 58.7\% (131) owned the family house while 36.3\% (81) were renting and 4.9\% (11) Others (e.g. Institutional homes). Majority of the adolescents had both their parents alive $76.7 \%$ (171), partial orphans $20.7 \%$ (35), total orphans $4 \%$ (9), and 3.6\% (8) did not know if their parents were alive.

Majority of the caregiver had Secondary $39.8 \%$ (88) as their highest level of education; $25.8 \%$ (57) with tertiary/technical, $25.3 \%$ (56) primary, and no formal education for $9.1 \%(20)$. Majority of the caregivers were Self-employed $34.7 \%$ (77), $17.1 \%$ (38) were public servants, $16.2 \%$ (36) were peasant farmers. The family level of income per month for the majority was 20-80 USD for $31.4 \%$ (70) while $26.9 \%$ (60) earned 80-140 USD and > 140 USD and 14.8\% (33) earned less than 20 USD. Majority of the adolescents perceived social support from a significant other $74.4 \%(166)$ and family $67.7 \%(151)$ to be their greatest sources of support while they perceived friends $32.7 \%$ (73) to be the least supportive. For seizure related characteristics, almost half $100(44.5 \%)$ had suffered seizure related physical injuries and $114(51.1 \%)$ reported a family history of epilepsy. More details are shown in Table 2. 
Table 2

Seizure related characteristics among adolescents with epilepsy at Butabika and Mulago Hospitals.

\begin{tabular}{|c|c|c|}
\hline Characteristic & $\begin{array}{l}\text { Frequency } \\
(n=223)\end{array}$ & Percentage (\%) \\
\hline \multicolumn{3}{|c|}{ Number of seizures in the last year } \\
\hline $\begin{array}{l}0 \\
1\end{array}$ & $\begin{array}{l}7 \\
24\end{array}$ & $\begin{array}{l}3.1 \\
10.8\end{array}$ \\
\hline $2-10$ & 97 & 43.5 \\
\hline$>10$ & 95 & 42.6 \\
\hline \multicolumn{3}{|c|}{ Age at onset of epilepsy } \\
\hline$<5$ years & 82 & 36.8 \\
\hline $5-10$ years & 97 & 43.5 \\
\hline$>10$ years & 44 & 19.7 \\
\hline \multicolumn{3}{|c|}{ How long have you had epilepsy } \\
\hline$<1$ year & 17 & 7.6 \\
\hline $1-5$ years & 73 & 32.7 \\
\hline $5-10$ years & 86 & 38.6 \\
\hline$>10$ years & 47 & 21.1 \\
\hline \multicolumn{3}{|c|}{ Number of anti-epilepsy drugs taken } \\
\hline None & 41 & 18.4 \\
\hline One & 120 & 53.8 \\
\hline Two & 57 & 25.6 \\
\hline More than two & 5 & 2.2 \\
\hline \multicolumn{3}{|c|}{ Duration on anti-epilepsy drugs } \\
\hline Never & 25 & 11.2 \\
\hline$<1$ year & 46 & 20.6 \\
\hline $1-5$ years & 87 & 39.1 \\
\hline $5-10$ years & 52 & 23.3 \\
\hline$>10$ years & 13 & 5.8 \\
\hline
\end{tabular}




\begin{tabular}{|lll|}
\hline Characteristic & $\begin{array}{l}\text { Frequency } \\
(\mathbf{n = 2 2 3 )}\end{array}$ & Percentage (\%) \\
\hline How often do you miss anti-epilepsy drugs & & \\
\hline Never miss & 89 & 39.9 \\
\hline Once a week & 69 & 30.9 \\
\hline More than Once a week & 41 & 18.4 \\
\hline Not applicable (newly diagnosed) & 24 & 10.8 \\
\hline
\end{tabular}

Major depression and generalized anxiety disorders were the most prevalent psychiatric comorbidities among the participants. Further details of the psychiatric comorbidity are shown in the Fig. 1.

Coping strategies used among adolescents with epilepsy were use of emotional support, instrumental support, religion and active copingas shown in Fig. 2. Note that Substance Use for coping encompassed use of any substance including alcohol.

Bivariate analysis between adolescent and primary caregiver sociodemographic factors associated with suicidal behavior showed that the adolescent's sociodemographic factors that were significantly associated with suicidal behavior among adolescents with epilepsy included sex, age and highest level of education of the adolescent as summarized in the Table 3 below. 
Table 3

Adolescent and Primary Caregiver Sociodemographic factors associated with suicidal behavior among adolescents with epilepsy at Butabika and Mulago Hospitals

\begin{tabular}{|c|c|c|c|c|}
\hline Characteristic & $\begin{array}{l}\text { No suicidal } \\
\text { Behavior(n = } \\
155)\end{array}$ & $\begin{array}{l}\text { Suicidal } \\
\text { Behavior(n = } \\
68)\end{array}$ & OR $(95 \% \mathrm{Cl})$ & $\begin{array}{l}\text { P- } \\
\text { value }\end{array}$ \\
\hline \multicolumn{5}{|l|}{ Sex } \\
\hline Male & $94(76.4)$ & $29(23.6)$ & 1 & \\
\hline Female & $61(61.0)$ & $39(39.0)$ & $\begin{array}{l}2.07(1.2- \\
3.7)\end{array}$ & 0.014 \\
\hline \multicolumn{5}{|l|}{ Age } \\
\hline $10-13$ & $81(77.1)$ & $24(22.9)$ & 1 & \\
\hline $14-17$ & $74(62.7)$ & $44(37.3)$ & $2.0(1.1-3.6)$ & 0.020 \\
\hline \multicolumn{5}{|l|}{ Address } \\
\hline Rural & $64(71.1)$ & $26(28.9)$ & 1 & \\
\hline Urban & $91(68.4)$ & 42(31.6) & $1.1(0.6-2.0)$ & 0.669 \\
\hline \multicolumn{5}{|l|}{ Tribe } \\
\hline Ganda & $95(70.9)$ & $39(29.1)$ & 1 & \\
\hline Nyankole & 12(57.1) & $9(42.9)$ & $1.8(0.7-4.7)$ & 0.210 \\
\hline Others & 48(70.6) & $20(29.4)$ & $\begin{array}{l}1.0(0.53- \\
1.9)\end{array}$ & 0.964 \\
\hline \multicolumn{5}{|l|}{ Highest level of education } \\
\hline None/Primary & $120(75.0)$ & $40(25.0)$ & 1 & \\
\hline Secondary/Tertiary & $35(55.6)$ & $28(44.4)$ & $2.4(1.3-4.4)$ & 0.005 \\
\hline \multicolumn{5}{|l|}{ Primary caregiver } \\
\hline Both parents & $80(74.1)$ & $28(25.9)$ & 1 & \\
\hline Single parent & $47(66.2)$ & $24(33.8)$ & $1.5(0.8-2.8)$ & 0.257 \\
\hline Others & $28(63.6)$ & $16(36.4)$ & $1.6(0.8-3.5)$ & 0.200 \\
\hline \multicolumn{5}{|c|}{ Primary care giver Sociodemographic Characteristics } \\
\hline \multicolumn{5}{|l|}{ Marital status of caregiver } \\
\hline Single/Separated/divorced/widowed & $63(70.0)$ & $27(30.0)$ & 1 & \\
\hline
\end{tabular}




\begin{tabular}{|c|c|c|c|c|}
\hline Characteristic & $\begin{array}{l}\text { No suicidal } \\
\text { Behavior( } \mathrm{n}= \\
155)\end{array}$ & $\begin{array}{l}\text { Suicidal } \\
\text { Behavior( } \mathrm{n}= \\
68)\end{array}$ & OR $(95 \% \mathrm{Cl})$ & $\begin{array}{l}\mathrm{P}- \\
\text { value }\end{array}$ \\
\hline Married/cohabiting & $92(69.2)$ & $41(30.8)$ & $1.0(0.6-1.9)$ & 0.895 \\
\hline \multicolumn{5}{|c|}{ Family House Ownership } \\
\hline Rent & $55(67.9)$ & $26(32.1)$ & 1 & \\
\hline Own & $92(70.2)$ & $39(29.8)$ & $0.9(0.5-1.6)$ & 0.721 \\
\hline Others & $8(72.7)$ & $3(27.3)$ & $0.8(0.2-3.2)$ & 0.747 \\
\hline \multicolumn{5}{|l|}{ Both Parents alive } \\
\hline No & $31(70.5)$ & 13(29.5) & 1 & \\
\hline Yes & $118(69.0)$ & $53(31.0)$ & $1.1(0.5-2.2)$ & 0.853 \\
\hline I do not Know & $6(75.0)$ & $2(25.0)$ & $0.8(0.1-4.5)$ & 0.794 \\
\hline \multicolumn{5}{|c|}{$\begin{array}{l}\text { Highest level of education of } \\
\text { caregiver }\end{array}$} \\
\hline None/ Primary & $46(60.5)$ & $30(39.5)$ & 1 & \\
\hline Secondary/ Technical & $109(74.2)$ & $38(25.9)$ & $0.5(0.3-1.0)$ & 0.037 \\
\hline \multicolumn{5}{|c|}{ Family level of income per month } \\
\hline$<80$ USD & $65(63.1)$ & $38(36.9)$ & 1 & \\
\hline 80-140 USD & $47(78.3)$ & 13(21.7) & $0.5(0.2-1.0)$ & 0.045 \\
\hline > 140 USD & $43(71.7)$ & $17(28.3)$ & $0.7(0.3-1.3)$ & 0.266 \\
\hline
\end{tabular}

Having a primary caregiver who had attained post primary education and higher family income (80-140 USD) was protective against suicidal behavior among the adolescents with epilepsy. Being an orphan was not associated with suicidal behavior. More details of the primary caregiver sociodemographic factors associated with suicidal behavior are shown in Table 3 at the end of this document.

Bivariate analysis for clinical factors (Psychiatric comorbidity and Seizure related factors) and suicidal behavior showed that besides major depression, all the other psychiatric comorbidities studied were not significantly associated with suicidal behavior (Psychotic disorder life time OR $=0.8295 \% \mathrm{Cl}(0.21-3.15)$ $P$ value $=0.77$, Psychotic disorder current $O R=3.9695 \% \mathrm{Cl}(0.53-29.30) \mathrm{P}$ value $=0.18$, Generalized anxiety disorder $\mathrm{OR}=0.97(0.46-2.01) \mathrm{P}$ value $=0.929$ while others had very few observations for comparison). Having had a seizure related physical injury or family history of epilepsy were also not significantly associated with suicidal behavior. Details shown in Table 4. 
Table 4

Clinical factors (Psychiatric comorbidity and Seizure related factors) associated with suicidal behavior among adolescents with epilepsy at Butabika and Mulago hospitals.

\section{Characteristic}

No suicidal Behavior $(\mathrm{n}=$ 155)

Major Depressive Episode

No

Yes

Number of seizures in the last year

0

1

2-10

$>10$

Age at onset of epilepsy

$<5$ years

5-10 years

$>10$ years

How long have you had epilepsy

$<5$ years

5-10 years

$>10$ years

Number of anti-epilepsy drugs taken

\begin{tabular}{lllll}
0 & $30(73.2)$ & $11(26.8)$ & 1 & \\
\hline 1 & $89(74.3)$ & $31(25.8)$ & $1.0(0.4-2.1)$ & 0.900 \\
\hline 2 & $36(58.1)$ & $26(41.9)$ & $2.0(0.8-4.6)$ & 0.120 \\
\hline Duration on anti-epilepsy drugs & & & & \\
$<1$ year & $30(65.2)$ & $16(34.8)$ & 1 & 0.316 \\
\hline $1-5$ years & $64(73.6)$ & $23(26.4)$ & $0.7(0.3-1.5)$ &
\end{tabular}

\section{Suicidal}

Behavior $(\mathrm{n}=$

68)
OR $(95 \% \mathrm{Cl}) \quad$ PValue

$\begin{array}{llll}135(82.8) & 28(17.2) & 1 & \\ 20(33.3) & 40(66.7) & 9.6(4.9- & < \\ & & 18.9) & 0.001\end{array}$

5(71.4)

19(79.2)

71(73.2)

$60(63.2)$

58(70.7)

68(70.1)

29(65.9)

62(68.9)

63(73.3)

30(63.8)

17(36.2)

$5(20.8)$

26(26.8)

$35(36.8)$

24(29.3)

29(29.9)

15(34.1)

28(31.1)

23(26.7)
0.7(0.1-3.7) 0.662

0.8(0.4-1.6)

0.524

$1.3(0.6-2.6) \quad 0.550$
$1.0(0.5-1.9) \quad 0.927$

1.3(0.6-2.7) 0.577
0.5(0.2-1.3) 0.145

$0.6(0.3-1.2) \quad 0.137$

1 


\begin{tabular}{|lllll|}
\hline Characteristic & $\begin{array}{l}\text { No suicidal } \\
\text { Behavior(n= } \\
\text { 155) }\end{array}$ & $\begin{array}{l}\text { Suicidal } \\
\text { Behavior(n= } \\
\text { 68) }\end{array}$ & OR (95\%Cl) & P- \\
\hline$>5$ years & $42(64.6)$ & $23(35.4)$ & $1.0(0.5-2.3)$ & 0.948 \\
\hline How often do you miss anti-epilepsy drugs & & & \\
\hline Never miss & $68(76.4)$ & $21(23.6)$ & 1 & \\
\hline Once a week & $48(69.6)$ & $21(30.4)$ & $1.4(0.7-2.9)$ & 0.335 \\
\hline More than Once a week & $21(51.2)$ & $20(48.8)$ & $3.1(1.4-6.8)$ & 0.005 \\
\hline
\end{tabular}

Bivariate analysis between perceived social support and suicidal behavior showed that adolescents who perceived their family $(O R=0.2 \mathrm{Cl}(0.1-0.4) \mathrm{p}$ value $<0.001)$, friends $(\mathrm{OR}=0.5 \mathrm{Cl}(0.2-0.9) \mathrm{p}$ value $=$ $0.026)$ and a significant other $(O R=0.50 \mathrm{Cl}(0.3-0.9) p$ value $=0.029)$ to be very supporting were less likely to have suicidal behavior when compared to those who did not feel supported. Bivariate analysis between coping strategies and suicidal behavior showed that coping by Substance use, acceptance (OR $=0.65 \mathrm{Cl}(0.36-1.22) \mathrm{p}$ value $=0 . \mathrm{d} 184)$, religion $(\mathrm{OR}=0.78, \mathrm{Cl}(0.44-1.37), \mathrm{p}$-value $=0.385)$, humor $(\mathrm{OR}=$ $1.59 \mathrm{Cl}(0.61-4.08) \mathrm{p}$-value $=0.336)$, behavioral disengagement $(\mathrm{OR}=1.57 \mathrm{Cl}(0.69-3.55) \mathrm{p}$-value $=$ $0.283)$, positive reframing $(\mathrm{OR}=0.6 \mathrm{Cl}(0.3-1.3) \mathrm{p}$-value $=0.20)$ and planning $(1.61(0.88-2.94) \mathrm{p}$-value $=$ 0.120 ) were not found to be significantly associated with suicidal behavior. Further details shown in table 5.

Table 5: Coping strategies associated with suicidal behavior among adolescents with epilepsy 


\begin{tabular}{|c|c|c|c|c|}
\hline Domain & $\begin{array}{l}\text { No suicidal behavior( } \mathrm{n}= \\
155)\end{array}$ & $\begin{array}{l}\text { Suicidal behavior }(\mathrm{n}= \\
68)\end{array}$ & OR(95\%Cl) & $\begin{array}{l}\mathrm{P} \text { - } \\
\text { value }\end{array}$ \\
\hline \multicolumn{5}{|c|}{ Self-distraction } \\
\hline No & $105(68.2)$ & 49(31.8) & 1 & \\
\hline Yes & $50(72.5)$ & 19(27.5) & $\begin{array}{l}0.8(0.4- \\
1.5)\end{array}$ & 0.521 \\
\hline \multicolumn{5}{|c|}{ Active coping } \\
\hline No & $77(62.1)$ & $47(37.9)$ & 1 & \\
\hline Yes & 78(78.79) & $21(21.2)$ & $\begin{array}{l}0.4(0.2- \\
0.8)\end{array}$ & 0.008 \\
\hline \multicolumn{5}{|l|}{ Denial } \\
\hline No & 133(71.1) & $54(28.9)$ & 1 & \\
\hline Yes & $22(61.1)$ & 14(38.9) & $\begin{array}{l}1.5(0.7- \\
3.3)\end{array}$ & 0.235 \\
\hline \multicolumn{5}{|c|}{$\begin{array}{l}\text { Use of Emotional } \\
\text { Support }\end{array}$} \\
\hline No & 41(59.4) & $28(40.6)$ & 1 & \\
\hline Yes & $114(74.0)$ & $40(26.0)$ & $\begin{array}{l}0.5(0.3- \\
0.9)\end{array}$ & 0.030 \\
\hline \multicolumn{5}{|c|}{$\begin{array}{l}\text { Use of Instrumental } \\
\text { Support }\end{array}$} \\
\hline No & $51(68.0)$ & $24(32.0)$ & 1 & \\
\hline Yes & 104(70.3) & $44(29.7)$ & $\begin{array}{l}0.9(0.5- \\
1.6)\end{array}$ & 0.728 \\
\hline \multicolumn{5}{|l|}{ Venting } \\
\hline No & $124(74.7)$ & $42(25.3)$ & 1 & \\
\hline Yes & $31(54.4)$ & $26(45.6)$ & $\begin{array}{l}2.5(1.3- \\
4.6)\end{array}$ & 0.005 \\
\hline \multicolumn{5}{|c|}{ Self-blame } \\
\hline No & $145(72.9)$ & $54(27.1)$ & 1 & \\
\hline Yes & $10(41.7)$ & $14(58.3)$ & $\begin{array}{l}3.8(1.6- \\
8.9)\end{array}$ & 0.003 \\
\hline
\end{tabular}

After multivariate logistic regression, highest level of education, major depressive episode, perceived family social support, active coping and venting were the variables that were statistically significantly 
associated with suicidal behavior. Details shown in table 6.

Table 6: Multivariate logistic regression model for the factors associated with suicidal behavior among adolescents with epilepsy at Butabika and Mulago Hospitals

\begin{tabular}{|llll|}
\hline Variable & Adjusted odds Ratio(aOR) & (95\% Confidence interval) & P-value \\
\hline Highest level of education & 1 & & \\
\hline None/primary & 2.2 & $(1.0-4.9)$ & 0.046 \\
\hline Secondary/tertiary & & & \\
\hline Major depressive episode & 1 & $(4.3-20.1)$ & \\
\hline No & 9.3 & & 0.001 \\
\hline Yes & & & 0.017 \\
\hline Perceived Family Social support & 1 & $(0.2-0.8)$ & \\
\hline No & 0.4 & & 0.033 \\
\hline Yes & & $(0.2-0.9)$ & \\
\hline Active coping & 1 & & 0.017 \\
\hline No & 0.4 & $(1.2-6.2)$ & \\
\hline Yes & 1 & & \\
\hline Venting & 2.7 & & \\
\hline No & & & \\
\hline Yes & & & \\
\hline
\end{tabular}

\section{Discussion}

\section{Prevalence of suicidal behavior among adolescents with epilepsy}

Almost one in every 3 adolescents with epilepsy attending Butabika and Mulago hospital clinic had suicidal behavior as indicated by a prevalence of $30.5 \%$ A study in Kaduna Nigeria, found the prevalence to be $20 \%$ among 170 adults with epilepsy [35]. This study is the only one in Sub Saharan Africa to investigate suicidal behavior among patients with epilepsy. There is still paucity of African studies reporting on this subject, in the studied population. Therefore, our study contributes to research on prevalence and factors associated with suicidal behavior among adolescents with epilepsy in subSaharan Africa. Research on suicidal behavior among adolescents with epilepsy is limited. A study in Iran 
among 1,169 adolescents aged 12-17 years who had attempted suicide, found $31(2.7 \%)$ that had had epilepsy. On assessing the suicidal behavior categories in our study population, 11 (4.9\%) adolescents reported suicidal attempt at least once in their life time. The Iranian study's inclusion criterion was every adolescent who had attempted suicide in a two-year period, looking for those who had epilepsy[36]. In our study, we sought to identify those who had suicidal behavior. This may explain the difference between our findings and the Iranian study.

In a Brazilian study of 139 people living with epilepsy aged 13 and older, the prevalence of suicidal thoughts was $39.6 \%$. Among those aged $13-41$ years, the prevalence was $14.4 \%$. This study grouped the respondents based on age into groups of those 13-41 years and 42 years and older. They used nonvalidated questions to ascertain their outcome of interest. These questions could have been difficult for the adolescents to fathom especially those who were youngest in the group. This could explain the difference between our findings and theirs[37]. In the USA, a study of 177 children and adolescents with epilepsy aged 5-16 years, 36 (20.3\%) reported suicidal ideation [38]. The difference with our study lies in the fact that children involved were younger and were less likely to have suicidal ideas than adolescents. Older children were more likely to have suicidal ideation as was in our study.

Another case control study in USA among 171 children and adolescents aged 5 to 16 -year-old, found suicidal ideation to be $20 \%$ higher in those with epilepsy than in the normal group [11]. The difference with our results may lay in the different objectives and study design and the fact that younger children were included in their study. We used the DSM IV-based version of the MINI-KID which includes questions on hopelessness and non-suicidal self-injury contributing to the scores of suicide risk. Some respondents had been feeling hopeless only without any death wishes, thoughts of suicide, plans or attempts. These might account for a prevalence that's higher than that seen in western studies noted above. Literature on adolescent suicidality, however, does strongly indicate that hopelessness and non-suicidal self-injury are often precursors to suicidal behavior [3].

\section{Factors associated with suicidal behavior among adolescents with epilepsy at Butabika and Mulago hospitals}

At bi-variate analysis, female adolescents with epilepsy are twice more likely to have suicidal behavior compared to the males as shown in Table 3. Older adolescents aged 14-17 years of age were also twice more likely to have suicidal behavior compared to their younger counterparts aged 10-13 years. Adolescents who had attained at least secondary school education were twice more likely to have suicidal behavior than those who had attained primary school education and no formal education at all. These findings may be explained by the fact that those adolescents with post primary education were more likely to be older adolescents who were found to have a higher prevalence of depression than their younger counterparts. Alternatively, it could be that the psychosocial challenges, role and identity crises are worst during the later years of adolescence. Having a chronic condition like epilepsy at such a time of 
life especially while in school where chances of being stigmatized are highest may make it a recipe for suicidal behavior.

Female adolescents were more likely to have suicidal behavior at bivariate analysis though this relationship dissipated at multivariate analysis. It is known that suicidal behavior is more common in females than in males and that females are more likely to attempt suicide. However, epilepsy being a chronic condition, adolescent sufferers, male or female might experience the same exposure to the biological and psychosocial mediators of suicidal behavior. One important negative finding in this study was that being an orphan was not associated with having suicidal behavior as we had anticipated. And this may be explained by the fact that adolescents with epilepsy may still be neglected or stigmatized with or without their parents. Further research is needed to explore this.

Having a primary care giver who had attained post primary education and higher family income (80-140 USD) was protective against suicidal behavior among the adolescents with epilepsy at bivariate analysis however this association did not hold at multivariate analysis. This could be explained by the fact that stigma to these adolescents with epilepsy may not change whether their caregivers have post primary education or have high family income. The adolescents may continue to feel isolated even when the family socioeconomic status is good because the interpersonal relationships may not necessarily be good as about $23.3 \%$ did not feel supported by their families.

In our study, the only seizure related factor that was significantly associated with suicidal behavior at bivariate analysis was poor adherence to anti epilepsy drugs, which was, missing medications more than once a week. Our findings show that suicidal behavior is not independently associated with seizure related factors. This was unexpected given most of the adolescents $(86.1 \%)$ had poor seizure control (2 to $>10$ fits a year). These finding were however similar to those found in a study on adults with epilepsy [39] contrary to two other studies; one done in Korea[40] and the other in Nigeria [35] showing that suicidal behavior was strongly associated with high seizure frequency. There is a paucity of data on the psychiatric impact on seizure-related variables in adolescents with epilepsy however in, adults, only a weak association between seizure frequency or AED poly-therapy and suicidal behavior has been reported $[41,42]$.

A population-based case-control study in Denmark, among suicide cases, 492(2.32\%) had had epilepsy and were 3 times more likely to commit suicide than their non-epileptic counterparts. The highest risk of suicide was identified in patients with epilepsy and comorbid psychiatric disease, even after adjusting for socioeconomic factors $(13.7,11.8-16.0 ; p<0.0001)$ [43]. In our study, adolescents who had major depression were 9 times more likely to have suicidal behavior than their counterparts who did not have depression. AB Ettinger, DM Weisbrot, EE Nolan, KD Gadow, SA Vitale, MR Andriola, NJ Lenn, GP Novak and BP Hermann [12] studied 43 children and adolescents (7-18 years of age) with epilepsy, but without known psychiatric comorbidity, attending an outpatient clinic at a pediatric neurological department. They reported that $26 \%$ of the sample had significantly increased depression scores and $16 \%$ had significantly increased anxiety scores. The findings were more pronounced in the older compared with the 
younger group. The high rate of depression in youth with epilepsy may explain the increased suicide rates $[11,12,44]$

Active coping and Use of emotional support as coping strategies were found to be protective against suicidal behavior whereas those who used venting were two times more likely to have suicidal behavior and those who used self-blame were three times more likely to have suicidal behavior than those who did not use these coping strategies. It was however only Active coping and Venting that remained statistically significant after logistic regression. Active coping was protective against suicidal behavior whereas coping with Venting was 2.7 times more likely to result in suicidal behavior. Venting would be expected to be protective since the adolescent talks about their feelings however our findings are to the contrary possibly because these adolescents may not be given a listening ear. This is important as many caregivers possibly get tired of listening to these complaints and hence ignore the plea for help.

The existing literature on the coping strategies employed by patients with epilepsy is sparse. Literature on coping strategies associations with suicidal behavior in epilepsy was hardly existent however, some studies have shown that patients with epilepsy frequently employ emotion-focused patterns of coping [16], particularly those with refractory epilepsy[45].Problem-focused coping mechanisms were generally preferred by people living with epilepsy compared to emotion-focused strategies $(p<0.05)$ in a Malaysian study[46].

In this study, adolescents with epilepsy who perceived their family, friends and significant other to be very supporting were less likely to have suicidal behavior when compared to those who did not feel supported. At multivariate analysis though, only perceived family support remained significantly protective against suicidal behavior. A study in Brazil including 10 children and adolescents with epilepsy aged 7 to 17 years attending a Clinic of Child Neurology, using the social support scale found that family was the major source of support [47]. Social support seems therefore to act as a protective factor for suicidal behavior of adolescents with epilepsy [48]. This supports our findings at multivariate analysis.

This is the first study on suicidal behavior among adolescent with epilepsy in Uganda and perhaps Africa at large. These findings provide information that can be used to create awareness about the burden of suicide which should prompt prevention strategies and abolition of discriminating policies for example criminalization of suicidal behavior.

The findings provide a springboard for further research on this subject in this region of the world.

We used the MINI-KID, an internationally recognized diagnostic instrument, on all adolescents with epilepsy who met the inclusion criteria.

Our study was one of the few studies looking at prevalence and factors associated with suicidal behavior among adolescents with epilepsy and had a comparatively larger sample size than most of those we found in our literature review. 
The findings of this study may not be generalizable to the general population because we did the study in the two national referral hospitals which means the participants might be sicker than those in the community hence inflating the prevalence of suicidality and psychiatric comorbidity.

Temporal relationships between epilepsy and suicidal behavior could not be established and so was causal associations. This is because outcome and exposure were measured the same time. However, regarding temporal relationships, it is likely that epilepsy preceded suicidal behavior as the majority had first time diagnosis at 6 years of age while suicidal behavior was more likely in older adolescents aged 14-17 years.

Recall bias caused by differences in the accuracy or completeness of the recollections retrieved by respondents regarding events or experiences from the past. This is a methodological issue due to use of interviews or questionnaires. We however had access to the medical records of the patients and this helped limit the recall bias to some extent. Selection bias arising from conveniently selecting all available participants which was the most feasible way to attain the sample size given available resources We did not classify the different types of epilepsy in this study. This could have gone a long way in informing us on which type is most at risk of getting suicidal behavior. We intend to do this is in subsequent studies.

\section{Conclusion}

The prevalence of suicidal behavior in adolescents with epilepsy was high. Major depression was most strongly associated factor with suicidal behavior. Having post primary education and using venting as a coping strategy increased the likelihood of suicidal behavior. Caregiver sociodemographic and seizure related characteristics were not associated with suicidal behavior. Perceived family social support and using the active coping strategy were protective against suicidal behavior.

The findings of this study may provide much needed knowledge on suicidal behavior and contribute to the reduction of negative attitudes about it. This study may further inform suicide prevention strategies in this population, contribute to research, clinical practice and policy change in ways such as these: first, integrating screening for suicidal behavior and major depression among adolescents with epilepsy should be made part of the routine care. This will offer faster identification and start of treatment for those with suicidal behavior. Secondly, designing interventions to enhance coping with epilepsy and family social support networks may help address the high prevalence of suicidal behavior and major depression among adolescents with epilepsy.

\section{List Of Abbreviations}

AED: Anti-Epilepsy Drugs; SB: Suicidal Behavior; ILAE: International League Against Epilepsy; WHO: World Health Organization; PWE: People With Epilepsy; MINI-KID: Mini International Neuropsychiatric Interview Children's version; DSM-IV-TR: Diagnostic and Statistical Manual of Mental disorders, Fourth Edition Text Revised; ICD 10: International Classification of Diseases version 10; USD: United States Dollars; K-SADS- 
PL: Kiddies Schedule for Affective Disorders and Schizophrenia - Present and Lifetime; CPS: Childhood partial seizures; CAE: Childhood absence epilepsy

\section{Declarations}

\section{Ethical approval and consent to participate}

Ethical approval was provided by the School of Medicine Research and Ethics Committee (SOMREC). Written informed consent was obtained from the caregivers and assent from the adolescents before enrolment into the study. Children and adolescents diagnosed with suicidal behaviors and psychiatric co morbidity were started on the appropriate treatment.

\section{Consent for publication}

Not applicable

\section{Availability of data and materials}

All data generated or analyzed during this study are included in this published article [and its supplementary information files].

\section{Competing interests:}

The authors declare that they have no competing interests.

\section{Funding}

This study was supported by the AfriPsycare organization. The funders had no role in the design of the study and collection, analysis and interpretation of data and in writing the manuscript.

\section{Author's contribution}

HK, CA, WM conceived and designed the study; HK performed the study HK and CA analyzed the data and drafted the manuscript. WM critically reviewed the manuscript for important intellectual content. All authors read, approved the final manuscript and agreed to be accountable for all aspects of the work in ensuring the questions related to the accuracy or integrity of any part of the work are appropriately investigated and resolved.

\section{Acknowledgements}

We thank the participants for accepting to participate in this study. We are also very grateful to the staff of the clinics for their support.

\section{Authors' information}


HK is a newly qualified Psychiatrist at Butabika National Mental Referral Hospital; WM is Associate Professor in the Department of Psychiatry, School of Medicine, College of Health Sciences, Makerere University; CA is a Senior Lecturer and a Child and Adolescent Psychiatrist in the Department of Psychiatry, School of Medicine, College of Health Sciences, Makerere University.

\section{References}

1. Toros F, Bilgin NG, Sasmaz T, Bugdayci R, Camdeviren H: Suicide attempts and risk factors among children and adolescents. Yonsei medical journal 2004, 45(3):367-374.

2. Pompili M, Girardi P, Tatarelli R: Death from suicide versus mortality from epilepsy in the epilepsies: a meta-analysis. Epilepsy \& Behavior 2006, 9(4):641-648.

3. Wild LG, Flisher AJ, Lombard C: Suicidal ideation and attempts in adolescents: associations with depression and six domains of self-esteem. Journal of adolescence 2004, 27(6):611-624.

4. Nordli DR, Jr.: Special needs of the adolescent with epilepsy. Epilepsia 2001, 42(s8):10-17.

5. Baker GA: Depression and suicide in adolescents with epilepsy. Neurology 2006, 66:S5-S12.

6. Johnson NB, Hayes LD, Brown K, Hoo EC, Ethier KA: CDC National Health Report: leading causes of morbidity and mortality and associated behavioral risk and protective factors-United States, 20052013. 2014.

7. Jones JE, Hermann BP, Barry JJ, Gilliam FG, Kanner AM, Meador KJ: Rates and risk factors for suicide, suicidal ideation, and suicide attempts in chronic epilepsy. Epilepsy \& Behavior 2003, 4:3138.

8. Kanner AM: Depression in epilepsy: prevalence, clinical semiology, pathogenic mechanisms, and treatment. Biological psychiatry 2003, 54(3):388-398.

9. Jones JE, Hermann BP, Barry JJ, Gilliam FG, Kanner AM, Meador KJ: Rates and risk factors for suicide, suicidal ideation, and suicide attempts in chronic epilepsy. Epilepsy \& behavior : E\&B 2003, 4 Suppl 3:S31-38.

10. Ott D, Caplan R, Guthrie D, Siddarth P, Komo S, Shields WD, Sankar R, Kornblum H, Chayasirisobhon $\mathrm{S}$ : Measures of psychopathology in children with complex partial seizures and primary generalized epilepsy with absence. Journal of the American Academy of Child \& Adolescent Psychiatry 2001, 40(8):907-914.

11. Caplan R, Siddarth P, Gurbani S, Hanson R, Sankar R, Shields WD: Depression and anxiety disorders in pediatric epilepsy. Epilepsia 2005, 46(5):720-730.

12. Ettinger AB, Weisbrot DM, Nolan EE, Gadow KD, Vitale SA, Andriola MR, Lenn NJ, Novak GP, Hermann BP: Symptoms of depression and anxiety in pediatric epilepsy patients. Epilepsia 1998, 39(6):595599.

13. Radhakrishnan $\mathrm{K}$ : Challenges in the management of epilepsy in resource-poor countries. Nature reviews Neurology 2009, 5(6):323-330. 
14. Besag F, Caplan R, Aldenkamp A, Dunn DW, Gobbi G, Sillanpaa M: Psychiatric and Behavioural Disorders in Children with Epilepsy (ILAE Task Force Report): Epilepsy and psychosis in children and teenagers. Epileptic disorders : international epilepsy journal with videotape 2016.

15. Nilsson L, Ahlbom A, Farahmand BY, Åsberg M, Tomson T: Risk factors for suicide in epilepsy: a case control study. Epilepsia 2002, 43(6):644-651.

16. Oosterhuis A: Coping with epilepsy: the effect of coping styles on self-perceived seizure severity and psychological complaints. Seizure 1999, 8(2):93-96.

17. Amir M, Roziner I, Knoll A, Neufeld MY: Self-efficacy and social support as mediators in the relation between disease severity and quality of life in patients with epilepsy. Epilepsia 1999, 40(2):216-224.

18. Maiga Y, Albakaye M, Diallo LL, Traore B, Cissoko Y, Hassane S, Diakite S, Clare McCaughey K, Kissani N, Diaconu V et al: Current beliefs and attitudes regarding epilepsy in Mali. Epilepsy \& behavior : E\&B 2014, 33:115-121.

19. Mbuba CK, Ngugi AK, Fegan G, Ibinda F, Muchohi SN, Nyundo C, Odhiambo R, Edwards T, Odermatt P, Carter JA et al: Risk factors associated with the epilepsy treatment gap in Kilifi, Kenya: a crosssectional study. The Lancet Neurology 2012, 11(8):688-696.

20. Mbuba CK, Ngugi AK, Newton CR, Carter JA: The epilepsy treatment gap in developing countries: a systematic review of the magnitude, causes, and intervention strategies. Epilepsia 2008, 49(9):14911503.

21. Wilmshurst JM, Cross JH, Newton C, Kakooza AM, Wammanda RD, Mallewa M, Samia P, Venter A, Hirtz D, Chugani H: Children with epilepsy in Africa: recommendations from the International Child Neurology Association/African Child Neurology Association Workshop. J Child Neuro/ 2013, 28(5):633-644.

22. Wilmshurst JM, Kakooza-Mwesige A, Newton CR: The challenges of managing children with epilepsy in Africa. Seminars in pediatric neurology 2014, 21(1):36-41.

23. Kinyanda E, Wamala D, Musisi S, Hjelmeland H: Suicide in urban Kampala, Uganda: a preliminary exploration. Afr Health Sci 2011, 11(2):219-227.

24. Mishara BL, Weisstub DN: The legal status of suicide: A global review. International journal of law and psychiatry 2016, 44:54-74.

25. Butabika Hospital Home Page [http://www.butabikahospital.com/] Accessed on $17^{\text {th }}$ May 2016.

26. Kish L: Sampling Organizations and Groups of Unequal Sizes. Am Sociol Rev 1965, 30:564-572.

27. Sheehan DV, Sheehan KH, Shytle RD, Janavs J, Bannon Y, Rogers JE, Milo KM, Stock SL, Wilkinson B: Reliability and validity of the mini international neuropsychiatric interview for children and adolescents (MINI-KID). The Journal of clinical psychiatry 2010.

28. Okello J, Onen TS, Musisi S: Psychiatric disorders among war-abducted and non-abducted adolescents in Gulu district, Uganda : a comparative study : original article. African Journal of Psychiatry 2007, 10(4):225-231. 
29. Kinyanda E, Kizza R, Abbo C, Ndyanabangi S, Levin J: Prevalence and risk factors of depression in childhood and adolescence as seen in 4 districts of north-eastern Uganda. BMC international health and human rights 2013, 13(1):19.

30. Nalugya-Sserunjogi J, Rukundo GZ, Ovuga E, Kiwuwa SM, Musisi S, Nakimuli-Mpungu E: Prevalence and factors associated with depression symptoms among school-going adolescents in Central Uganda. Child and Adolescent Psychiatry and Mental Health 2016, 10(1):39.

31. Carver CS: You want to measure coping but your protocol's too long: consider the brief COPE. Int $J$ Behav Med 1997, 4(1):92-100.

32. Muliira RRS: The effects of occupational exposure to maternal deaths on the well-being of professional midwives in rural Uganda. Thesis. Pretoria: University of South Africa; 2014.

33. Zimet GD, Dahlem NW, Zimet SG, Farley GK: The Multidimensional Scale of Perceived Social Support. Journal of Personality Assessment 1988, 52(1):30-41.

34. Nakigudde J, Musisi S, Ehnvall A, Airaksinen E, Agren H: Adaptation of the multidimensional scale of perceived social support in a Ugandan setting. Afr Health Sci 2009, 9 Suppl 1:S35-41.

35. Nuhu FT, Lasisi MD, Yusuf AJ: Suicide risk among adults with epilepsy in Kaduna, Nigeria. General hospital psychiatry 2013, 35(5):517-520.

36. Zamani G, Mehdizadeh M, Sadeghi P: Attempt to Suicide in Young Ages with Epilepsy. Iranian Journal of Pediatrics 2012, 22(3):404-407.

37. Stefanello S, Marín-Léon L, Fernandes PT, Min LL, Botega NJ: Suicidal thoughts in epilepsy: a community-based study in Brazil. Epilepsy \& Behavior 2010, 17(4):483-488.

38. Jones JE, Siddarth P, Gurbani S, Shields WD, Caplan R: Screening for suicidal ideation in children with epilepsy. Epilepsy \& Behavior 2013, 29(3):521-526.

39. Hecimovic H, Santos J, Carter J, Attarian H, Fessler A, Vahle V, Gilliam F: Depression but not seizure factors or quality of life predicts suicidality in epilepsy. Epilepsy \& Behavior 2012, 24(4):426-429.

40. Lim H-W, Song H-S, Hwang Y-H, Lee H-W, Suh C-K, Park S-P, Kwon S-H: Predictors of suicidal ideation in people with epilepsy living in Korea. Journal of Clinical Neurology 2010, 6(2):81-88.

41. Kalinin VV, Polyanskiy DA: Gender and suicidality prediction in epilepsy. Epilepsy \& Behavior 2005, 7(4):657-663.

42. Nilsson L, Tomson T, Farahmand BY, Diwan V, Persson PG: Cause-specific mortality in epilepsy: a cohort study of more than 9,000 patients once hospitalized for epilepsy. Epilepsia 1997, 38(10):1062-1068.

43. Christensen J, Vestergaard M, Mortensen PB, Sidenius P, Agerbo E: Epilepsy and risk of suicide: a population-based case-control study. The Lancet Neurology 2007, 6(8):693-698.

44. Oguz A, Kurul S, Dirik E, Eylül D: Relationship of epilepsy-related factors to anxiety and depression scores in epileptic children. Journal of Child Neurology 2002, 17(1):37-40.

45. Krakow K, Buhler K, Haltenhof H: Coping with refractory epilepsy. Seizure 1999, 8(2):111-115. 
46. Lua P, Neni W, Samira T: Coping With Epilepsy: How Do They Influence Health-Related Qualityof Life (Hrqol)? International Journal of Psychosocial Rehabilitation 2012, 16.

47. Oliveira N, Zanni K: 051-(OLI0149) Social support perception in children and adolescents with epilepsy. Epilepsy \& Behavior 2014, 38:203-204.

48. Siqueira NF, Guerreiro MM, Souza EAPd: Self-esteem, social support perception and seizure controllability perception in adolescents with epilepsy. Arquivos de neuro-psiquiatria 2011, 69(5):770774.

Figures 


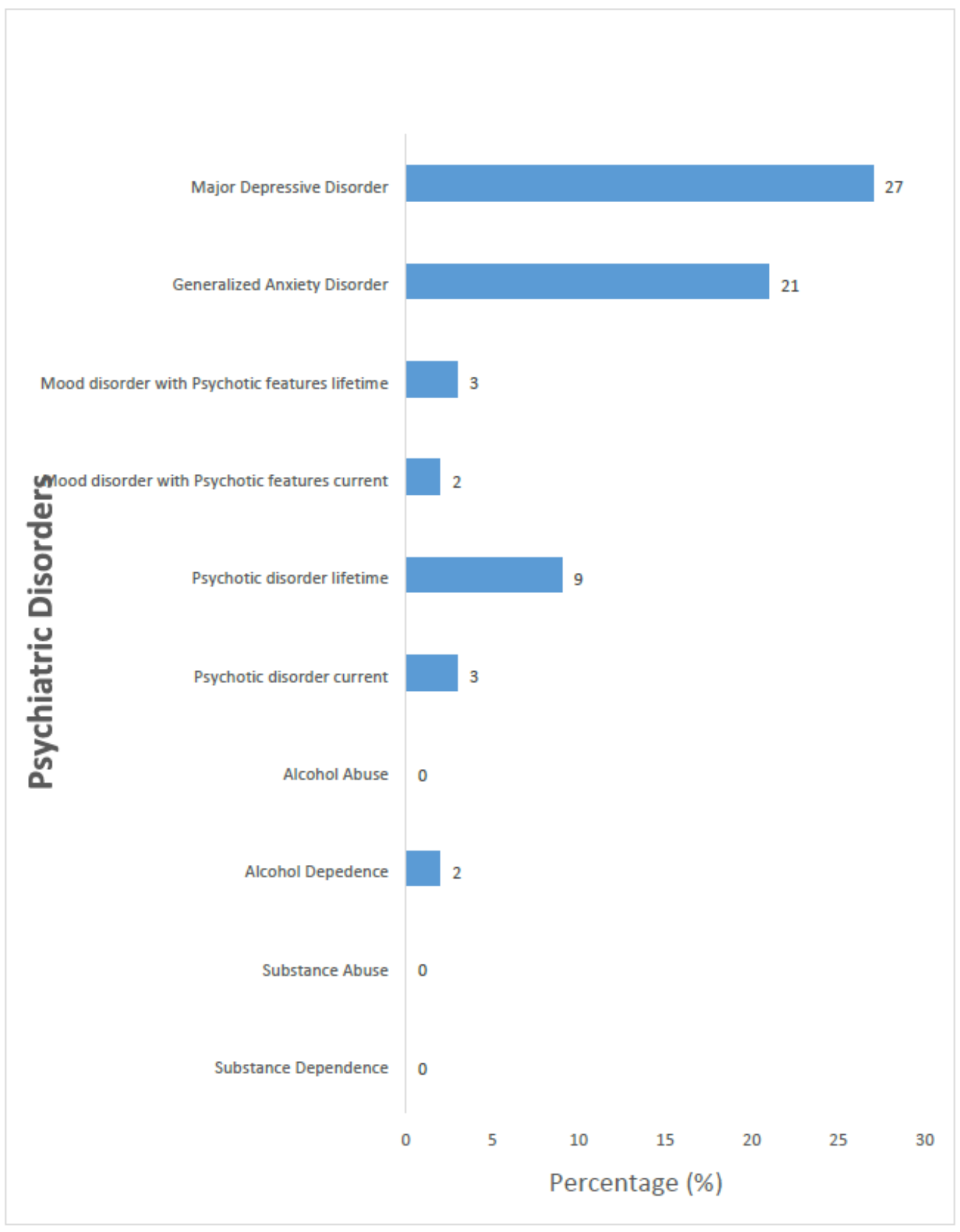

\section{Figure 1}

A bar graph showing psychiatric comorbidity among adolescents with Epilepsy at Butabika and Mulago hospitals. 


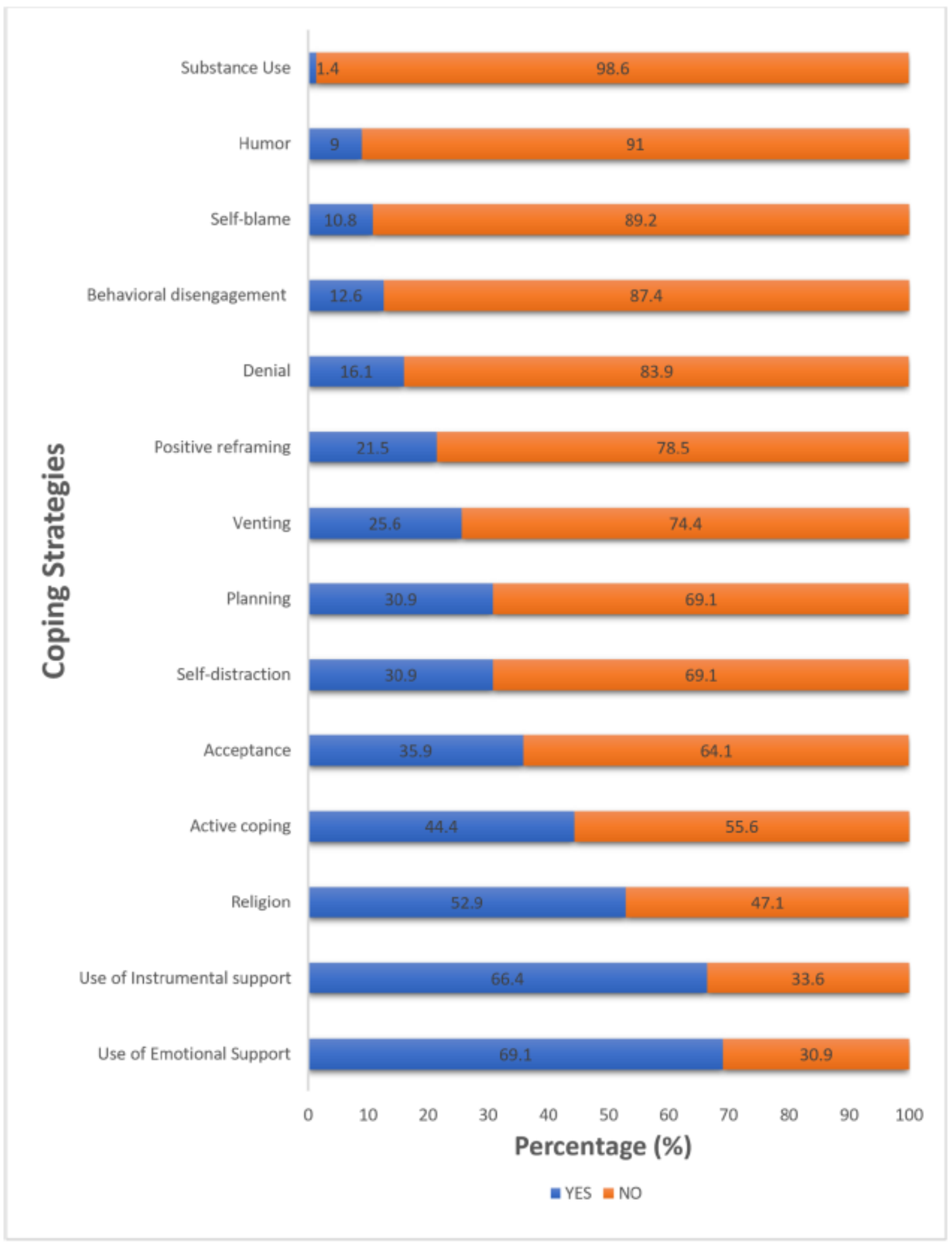

Figure 2

Coping Strategies among adolescents with epilepsy at Butabika and Mulago hospitals. 